\title{
Issues of Human Beings Trafficking in Albania*
}

\author{
Jashar Vreka
}

\begin{abstract}
The theme of trafficking of human beings treats one of the most severe and dangerous criminal phenomena of the organized crime in Albania. The objects of this paper are: human trafficking; ways of trafficking; risk of Albanian society; and investment of the criminal benefits deriving from trafficking in legal economic activities. It is of great importance for the treatment of proactive investigations to the trafficking of human beings. Another important aspect of the trafficking investigations is the investigation of criminal assets and the way how they are used in the economy of the country. In this paper, we stress that the investigation of criminal assets benefited by the crime of trafficking human beings as well as other wealth financed by these assets is important as the investigation of the criminal activity of trafficking itself. Also, we aim to evaluate the necessity of acting of all law enforcement agencies and other state institutions in order to be successful in the fight against the crime of trafficking of human beings. At the end of this paper, we do treat the necessity and the ways of collaboration of law enforcement agencies, NGOs, and structures of local government for rehabilitation of the victims of trafficking and their integration in the social life.
\end{abstract}

\section{Keywords}

Trafficking, human beings, organized crime, proactive investigations, criminal assets

In a summarized way, we will present a short history on criminal activity in the field of human trafficking in Albania.

The crime of human trafficking appeared at the beginning of $90^{\prime}$.

Before 1990, in Albania was installed the dictatorial state which was the controller and the possessor of all political, economical, and social life of Albanian society.

Before 90', we had no private property and economical freedom.

At the same time, there was no political freedom, the rights of human beings, a total lack of the relations with other western and non-western countries, and the free movement of people abroad. Phenomena such as migration and asylum for foreign citizens towards Albania or of the Albanians to other countries did not exist.
From the point of social view and heritage, Albanian society inherited a backward mentality about the position of woman in society. The moral and old mores inherited from the past can be defined as a general social level of development which was very low.

In its tradition, Albania had no experience at all related aspects that could be defined as the most liberal parts of a society.

Thus, Albania had no history with the developments happening to other countries, where the "extremes" of the human freedom and rights asked for

aSecurity Academy, Albania

Correspondent Author:

Jashar Vreka, Street "Hajdar Hidi" Nr. 60/12, Tirana, Albania 
dilatation and liberalization of sexual freedom, the right of a person to choose a profession, and spreading of the free professions including the prostitution as well.

Coming from a total closed and undeveloped society in the social field, with half of a population, female, who did not enjoy almost any personal freedom in her life, with an urban highlighted backwardness, with approximately $90 \%$ peasant population, and with a very poor economy which insists to secure the food as emergency, Albania enters into the cycle of development after the World War II.

The dictatorial system set in Albania did some enhancements from the inherited past related with the position of the woman in society, education, and employment which was to the interest of the regime itself. The communist regime did almost nothing to the respect of freedom and human rights, females included, so based on this point of view, the position of the woman remained in non-developed ones especially her position in the family.

There were some criminal phenomena related to the field of prostitution but they were very sporadic and often they were covered and were not presented to the population as the system called them as a failure of the communist education.

These were the circumstances of the socio-economic development and human rights and freedom development up to 1990 , a year that points the fall of communist regime.

After 90', we had important democratic changes to the development of human freedom and rights, political and economical freedom as well.

Free movement of the persons towards western countries was accompanied with a flow of clandestine migration looking for new economic resources. The massive migration of the first years, 1990-1991, is a little bit unlawful but it still goes on.

Based on above explanation, trafficking of human beings in Albania may be separated into two phases.

\section{FIRST PHASE, PERIOD FROM 1991 UP TO 2001}

The period after 1991 up to 2001 noticed an instant development regarding the freedom and human rights, freedom of speech, freedom of movement, property, economical freedom, etc. so, Albania sets contacts with other countries around due to the free movement. We had a big migration especially towards the western countries mainly for economic reasons. At the same time, we started trade exchanges with Italy, Greece, and Turkey.

Free movement, poor economy, ignorance of foreign world, and lack of information were premises used by organized crime and traffickers of human beings for recruiting the victims through enticement of working abroad, faked marriages, even by using threats.

The Albanian state and law enforcement agencies and the judicial bodies were found unprepared in front of this new situation due to the lack of legislation, professionalism, and anti-trafficking structures. There have done some enhancements in the legislation through the constitutional package during 1992-2001 but those changes were not enough yet. Growing of professionalism and setting of anti-trafficking structures need their time and due to the limitations mentioned above, Albania was addressed as a country of origin and transit regarding the trafficking of the victims.

Under those conditions, we did some essential legal improvements in the fight against trafficking of human beings in the year 2001 .

\section{SECOND PHASE, FROM 2001 UP TO NOW}

During 2001, we noticed a qualitative time against the fight of criminal activity of human trafficking. We had some sensitive improvements in the legislation in the field of anti-trafficking of human beings. Albanian penal legislation includes a set of articles considering 
trafficking of human beings as a figure of crime in the field of penal deeds of organized crime, foreseeing special articles for children and women trafficking, trafficking more than one time and with serious consequences. They foresee the economic punishment and penal one as well, thus enabling fighting this criminal activity in its strongest point that is money coming out from this criminal activity.

Immediately after the approval of legal changes of 2001 by the law enforcement agencies in close collaboration with the General Prosecutors' Office and being strongly supported by MAPE (Multinational Advisory Police Element) Mission, IOM (International Organization For Migration), and UNHCR (United Nations High Commissioner for Refugees), it initiated a vast campaign for training the officers of judiciary police of state police and prosecutors, especially members of anti-trafficking structures and structures of border police who were the first officials facing the flows of returned persons from EU countries and especially women and children.

Setting and structuring and training of law enforcement agencies brought positive results and at the time during the period of 2001-2003, we noticed a considerable growth of identification, investigation, and fighting the criminal activity of trafficking of human beings and sequestration of the assets deriving from this criminal activity.

During this period, we had a close collaboration between law enforcement agencies and courts in that field.

Another success of that period was setting of the accommodation and rehabilitating centers for the victims of trafficking. These centers were very well equipped with the basic elements, helping to the economical status, improving the necessary conditions to rehab, and putting the victims in better living and working conditions.

Despite the legal activities and initiatives taken in the field of fighting trafficking from Albanian governments, and permanent support and aid of
American governments and European ones through missions and police and judiciary assistance programs, trafficking of human beings is still a very severe problem in Albania.

This easily verified through the annual reports of State Department: in Trafficking in Persons Report 2012, "Albania is primarily a source country for men, women, and children subjected to sex trafficking and forced labor, including the forced begging of children. Albanian women and children continue to be subjected to sex trafficking within the country"; in Trafficking in Persons Report June 2016, "Albania is a source and destination country for men, women, and children subjected to sex trafficking and forced labor", as well as the reports of EU and EUROPOL (European Police Office) regarding criminality. These institutions stress the improvements and they still notice that Albania is yet a country of origin and transit for trafficking of human beings and especially trafficking of women for sexual exploitation and children involved into criminal activity.

Based on this situation, we want to present some suggestions which could be applied and improve the efficiency of the work of law enforcement agencies in their fight against trafficking of human beings.

We think that the following suggestions are effective in realizing the state strategies against trafficking of human beings and they will improve the following objectives:

(1) Reducing the number of trafficked persons;

(2) Growing the number of investigations against traffickers;

(3) Growing the number of sequestration of traffickers and their collaborators;

(4) Further improving of the accommodation and rehab centers for the victims of trafficking;

(5) Improving the state training and working policies of the victims of trafficking;

(6) Final extract of Albania from the map of problematic countries regarding trafficking of human beings. 


\section{IN THE FIELD OF LEGISLATION}

Governmental institutions and especially the law enforcement and judicial ones need to seriously take into consideration that in the investigation of the criminal activity of trafficking of human beings, the most important part is the investigation of wealth and criminal assets deriving from those criminal activities.

Investigation and criminal punishment would be not enough if the criminals will possess their wealth and they will try to go through their collaborators, relations, and investments, growing their criminal wealth.

Possessing of wealth by the traffickers after they have been punished by a court process keeps in itself some negative and dangerous impacts.

Firstly, possessing of criminal wealth is a continuous danger for economy because this wealth may be laundered at any time and later they will be part of the legal productive and trade business activities.

Secondly, laundering of the criminal income and their channelizing and diversification into business is a very important means for the punished traffickers in collaboration with their relations to keep their criminal activity going, preventing the justice to reach its objective that is interruption of their criminal activity in that field.

Thirdly, possessing of the wealth from the traffickers and their collaborators is a permanent danger for corrupting the police and justice system, for symbolic punishments, threatening of the witnesses, falsification of evidences, etc.

Light punishments, early releases, and benefits from legal economic activities make a worse picture to the victims of trafficking and their relatives and to some extent to a part of citizens as well. This bad image is perceived as:

(1) A lack of justice for criminals;

(2) Corruption of the state and its structures.
The abovementioned perceptions create some ideas to the victims that they are unsaved and unprotected; they create the idea that the traffickers are suffering light punishments and this phenomenon leads to a lower collaboration of the community with the police and justice system.

We think that the anti-mafia law approved on December 3, 2009 would be effective if the investigation of the criminal wealth would be done by the same structure involved in the penal investigation or by prosecutors attached to the main structure of penal investigation having full attributes of investigation (not attributes of formal verification). Unfortunately, since the approval of that law taking into consideration some improvements done in 2014, we have achieved some small results.

We are of the opinion that the victims of trafficking have to profit something from the sequestered wealth according to an approved legislation.

\section{IN THE FIELD OF PENAL INVESTIGATION}

Investigation of the crime of trafficking of human beings is very hard and especially for the countries of origin and transit. The criminal activity of trafficking is done generally in two parts: The first part is that of recruitment and a part of transportation of the victims is done in the country of origin and the second part is the accommodation and exploitation which is realized in one or other countries. Penal investigation of trafficking in its three phases which are the recruitment, transportation, and accommodation and exploitation of the victims creates duration and leads to carry out a full investigation from two police structures of different countries (police structures of the country of origin and police structures of the country where the victim is exploited). Often, due to the impossibility of cooperation in the field of information, the police and prosecutors structures of the countries of origin of trafficking are obliged to 
investigate only the phase of recruitment and based on these evidences, they will put the case in front of the court; while the police of the waiting country where the victims are exploited for prostitution can verify only the crime of sexual exploitation, not the trafficking.

Causes that have a negative impact on a full investigation of the crime of trafficking are:

(1) The relatively long period from the moment of recruitment up to the exploitation of the victim creates a gap in the investigation and possibility that the evidences of recruitment are loose or changed;

(2) Investigation from two or more law enforcement structures of different countries;

(3) Investment of the criminal profits in a long time period in different countries.

This brings a necessity especially for law enforcement agencies of the countries of origin to focus in and to enhance the proactive investigations of recruitment of the victims. Intensification of proactive investigations brings bigger opportunities in securing legal evidences for the criminal activity and at the same time, it does not create a gap between the moment of recruitment of the victim and the traffic ants. This is included as one of the recommendations of annual report of State Department, in Trafficking in Persons Report 2012, recommendations for Albania are: “...proactively implement the new standard operating procedures on victim identification to increase the scope of victims identified in Albania".

Indicia for proactive investigations are related with some activities of judiciary police providing prior information without waiting the denouncement of the victim to start the investigations.

Such activities include:

(1) Verifications of local police for unmotivated departures of different persons mainly females and children without a certain address, suspicious address, or in unknown destinations;

(2) Preliminary verifications in the cases of hesitation from the relatives of females or children to give explanations about the state, city, or the address or the time of departure and the way as well;

(3) Verification of the persons (contacts) who are seen or are suspicious that they have contacted the departed person before the moments of departure from the house, school, working post in an unknown destination;

(4) Verification of the printed offers, distributed in social nets or in verbal way in the area for employment abroad, participating in contents abroad, part-time employment especially for females and the verification of the sponsors as employment agencies, tour agencies, and other suspicious subjects;

(5) Verification of the persons presenting themselves as candidates for engagement and marriage with females to go and live abroad;

(6) Verification of the wealth of the persons and their relatives, suspicious as persons who have had their impact on or have travelled together with the person suspicious as the victim;

(7) Verification of the economical activities risen in a short period of time, which are not justified from the persons or families who do not have enough income thus being suspicious as being engaged in the organization of the trafficking of human beings.

\section{INTERNATIONAL COOPERATION OF LAW ENFORCEMENT AGENCIES}

The important role in the investigation of the criminal activities in trafficking of human beings is the cooperation between the law enforcement agencies of the countries of origin and the countries where the exploitation is carried out. We are of the opinion that having an effective cooperation besides sharing information between those agencies would be more effective in the rising of some operational nuclei or direct contacts in the anti-trafficking structures for special cases in sharing the information between them. This practice will raise the cooperation in sharing official information directly by the leaders of those 
structures. This will lead to a better planning of the common operations. We think that this kind of procedure will prevent the delay of sharing information into offices of international police cooperation and enhancing the efficiency in concrete investigations activities.

\section{INTER-INSTITUTIONAL COOPERATION}

Verification, sequestration, and seizure of the wealth deriving from the criminal activity of trafficking of human beings is a very important part of bringing them in front of the court and their punishment. Prison sentencing of the traffickers and no sequestration and seizure of their wealth deriving from this criminal activity is the same thing as you will give the traffickers half of the punishment or less.

There is a negative perception related to the punishment given to the traffickers and the ongoing formal and informal economical activities through their collaborators or family members. This negative perception is addressed to police, prosecutors, and judicial system, figuring them out as corrupted institutions and the result is a lowering collaboration of the victims or communities to denounce them.

In order to carry out a full investigation of the criminal activities in the field of trafficking of human beings and especially for the investigation of criminal wealth deriving from the trafficking, it is very urgent for the inter-institutional collaboration of such institutions such as the directorate of taxes, custom directorate, directorate of money laundering, and the system of the second level of banks. We are of the opinion that this cooperation is not able to give results in the way how it is thought and the way of current acting. The mutual cooperation and obligation of institutions included in those investigations need to be sanctioned with some specific legal acts for the activity and responsibilities of each institution.

A very good example of the necessity of cooperation between institutions engaged in the fight against organized crime (trafficking of the human beings as a part of it) is the case of Al-Capone where the evidences that brought him in front of the court were his wealthy assets and he was punished for tax evasion!!!

The case of Al-Capone before 70 years is a very important lesson to the investigation of criminal wealth which asks for an engagement in such investigations of state structures such as taxation institutions, custom institutions, and the directorate of money laundering.

It is well-known that a very big part of the criminal income deriving from exploitation of the victims of trafficking is entering into Albania to be laundered through different businesses.

Is economical activity not a part of supervision from the abovementioned institutions?

There is no indicia in the starting of verification of the wealth of criminal activities in investigations of the trafficking of human beings by the law enforcement agencies. There has been very difficult for the traffickers to justify the source of their money when they try to invest them into legal investments or businesses. It is exactly this unjustified investment without a legal source of their creation and tax evasion due to the lack of previous economical activity enabling the optimal possibility for starting the investigation against traffickers of human beings.

The absence of carrying out the investigations or executing out of formal and perfunctory investigations of the wealth and economical activities created by unjustified income or suspicious sources brings heavy consequences in the fight against trafficking of human beings.

The small bad thing is channelizing of the investigation of the wealth into a formal verification and an exchange of official correspondence between the institutions.

The worse consequence is a selective and abusive verification and investigation of the criminal wealth of the traffickers. This action may lead to the corruptive 
consequences for the institutions, inaction or disparity and weak results in the anti-trafficking fight.

As a conclusion-functioning of legal institutions and mechanisms in the economical field limits channelizing the criminal wealth deriving from criminal activities of organized crime and trafficking of human beings into legal businesses which have direct impact on lowering of criminal tendencies.

\section{IMPROVING ASPECTS OF TREATMENT OF VICTIMS OF TRAFFICKING}

There are two points of view of treatment of victims of trafficking.

The first and possible point of view to be measured is the institutional one represented by state and NGOs engaged in rehabilitation of the victims of trafficking.

The second point of view is that of victims related with the fact of how the victims of trafficking feel during rehabilitation and their expectations for their perspective into social integration.

Based on the first point of view on what the state has done for the social rehabilitation and integration of the victims of trafficking, we may say that:

We have a coordinated system protecting and helping the victims of trafficking for almost two decades.

Inside the state institutions, there is the Ministry of Social Matters which manages the state policies and helps the victims of trafficking. It is this ministry managing the social centers for trafficked victims. The other institution engaged in this process is the Ministry of Interior through the Coordinator of the Directorate of Anti-trafficking which coordinates all the information for trafficked victims.

There are some functional rehabilitation centers for victims of trafficking in Shkodra, Vlora, and Elbasani which are managed by NGOs.

These centers generally offer good conditions of accommodation for the victims.
These centers besides accommodation conditions offer at the same time a professional help for the victims through psychologists being attached to these centers.

These centers offer basic professional courses for updating the victims who do not have a profession enabling them to enjoy a working possibility after leaving those centers.

The conditions in these centers are improved year by year by the government. Lately, we have noticed a qualitative cooperation between governmental institutions and NGOs.

Is this enough for these victims?

We mentioned above the governmental and non-governmental structures which look after the trafficked victims. Each parameter mentioned above such as conditions of accommodations, psychological help, and professional update of the victims is improved continuously by growing state expenses and donations to their favor.

In Trafficking in Persons Report June 2016, recommendations for Albania are: “...increase funding to NGO-run shelters for trafficking victims and provide funding on a regular basis; improve services provided at the state-run shelter, particularly medical, psychological, and reintegration services".

At the end, all these activities are measured with the real fact of the victims to be engaged in normal and family life and their engagement in social life as well.

We have had cases that some of the victims after leaving these centers turn back again to trafficking, prostitution, or other criminal activities.

Some of the victims do not want to stay in the rehabilitation centers.

We think that the policies and rehabilitation centers of the trafficked victims need to change their concept and function. Having good conditions, the victim will think how to act after her/his rehabilitation and in the case when they do not see any light of what they have suffered, they are forced to prejudice 
themselves as an unlucky person with no perspective; it is most possible for them to turn back to the previous activity or to turn to a person living on begging and charity.

The rehabilitation centers are not treated as temporary accommodation and oasis of calm stations but as school to be equipped with knowledge and abilities to be integrated into society. As such, these centers need to offer, after staying possibilities for a job, economical help for their systematization, free post traumatic help up to their full recovery. This possible perspective needs to be cleared and well-explained to the victim since at the very beginning. Only under such conditions, the victim will seriously take her/his rehabilitation and perspective as well.

On the contrary, all governmental policies for rehabilitation and expenses may be considered by the victims as a temporary activity without any real value and it will be spoiled.

Another fact that we have to take into consideration is the Albanian social mentality towards the victims of trafficking and the impossibility of the victims to return and to be supported by the family.

This is not easy engagement to be realized but it is not impossible.

This real strategy of rehabilitation of the victims of trafficking may be implemented through social policies of the central and local government. Those policies are not going to be on voluntary basis (as such, they have the possibility not to be implemented on full basis); they need to be defined on proper legal grounds with the respective responsibilities of each institution and structure engaged in this strategy. These policies may include the triangle: government-local government—business.

We can involve the private business through facilitating policies, thus we will achieve a common partnership for employing victims of trafficking.

Providing free psychological help up to final rehabilitation of the victims after leaving the rehab centers will have not only a medical effect but also a social one as a continuous support of the state towards them.

Treatment of the victims with a special economical help from the state after leaving the rehab centers will give them more security and will prevent them to turn back to their previous activity.

\section{GENERAL RECOMMENDATIONS}

(1) Improving in the penal legislation and especially to the investigation of criminal assets deriving from the trafficking of human beings;

(2) Passing of criminal wealth created from the exploitation of the victims from the civil investigation as a part of penal investigation of the penal deed of trafficking;

(3) Enhancing the quality of professionalism of the proactive activity of the law enforcement agencies in the field of anti-trafficking;

(4) Enhancing the legal framework of the activity of tax, custom, and institution of money laundering in controlling the money deriving from trafficking of human beings;

(5) Setting inter-institutional cooperation for investigation of traffickers on well-defined activities and responsibilities for each institution engaged in that cooperation;

(6) Developing the direct cooperation of the law enforcement structures between states during investigation of trafficking of human beings;

(7) Improving on the strategy of the fight against trafficking of human beings and victims' integration and employment into Albanian society.

\section{Note}

* In this paper, we do not aim to analyze the work of any Albanian or foreign institution but we base on the problems noticed during the period after the 90' up to now for trafficking matters; we give conclusions in the form of recommendations for a continuous improvement in the 
legislation and the action of law enforcement agencies in the fight against trafficking of human beings. The thoughts and recommendations in the paper are of the author's view and as such they do not express the policy or the ideas of any institution.

\section{References}

Action Plan 2014-2017.

Action Plan for Social-Economic Reintegration of Women and Young Girls and Girls/Possible Victims of Trafficking 2015-2017.

Convention of European Council "For Measures Against Trafficking of Human Beings Ratified With the Law No. 9642".

Law no. 10192, date December 3, 2009. "For Prevention and Fighting Organized Crime, Trafficking and Corruption Through Preventive Measures Against Wealth".

Law no. 8733, date January 24, 2001. "For Some Changes and Additions in the Penal Code of RA". Articles 110/a, 114/b, 128/b.

New Changes in the Penal Code. Law no. 9188, date February 12, 2004.
Prime Minister's Order no. 179, date July 17, 2014. "For Setting of State Committee Against Trafficking of Persons".

Report for Realization of Albanian National Strategy of the Fight Against Trafficking of Human Beings. September 2008-May 2009.

Report on Implementation of Strategy Against Trafficking of Human Beings and Action Plan 2014-2017. October 2016.

State Department Report on Trafficking of Human Beings. June 30, 2016, paragraph, Albania.

State Department Report-Albania a Trafficking Country of Human Beings. June 20, 2012.

Strategy of Fight Against Trafficking of Persons Approved by the Decision of Prime Minister. No. 814, date November 26, 2014.

\section{Bio}

Jashar Vreka, MCS, police officer, chief of Continuous Training Department in Safety and Crime Investigation, Law Faculty, Security Academy, Tirana, Albania; research fields: criminal investigations, penal and procedural law, teaching and training police officers. 